\title{
CONSUMERS MUST BE PREPARED FOR BIOTECH PRODUCTS
}

B

iotechnology products are beginning to reach the marketplace at a time when the depth of technological illiteracy in the culture is only surpassed by the promise of unimaginable advances in the new technologies. Citizens of developed countries are confronted with an ever-widening gap between what manufacturers can do and what the public can understand. Despite the advent of the home computer, a general intolerance and distrust of new technology persists. In an era when evolution is being seriously challenged on campuses by popular evangelicals, when congressmen meet to debate when life begins and decide by consensus, when nuclear power plants are equated in the public mind with Hiroshima-like time bombs, an entire generation of biotechnology products is under refinement for testing and eventual distribution to the consumer. Unless industry begins to seriously address the problems in marketing these products to end users, the biotechnology community could suffer from the public resistance familiar to some of the older research-based industries, including the nuclear power industry.

In addition to the pervasive fear of change which accompanies the lack of understanding of technology, the common person currently brings to biotechnology a perception colored by science fiction fantasies of mutant monsters, clones of Hitler or dying millionaires, humanmonkey hybrid slaves, and other images of conspiracy between the wicked, the powerful, and the misguided but brilliant scientist. These potent media images emerged during the early debates on recombinant DNA experimentation. One can recall the battles fought in towns where gene-splicing entrepreneurs established their startup laboratories. The mayor of Cambridge, Massachusetts in early 1977 embodied that fear when he proclaimed: "we want to be damn sure that the people of Cambridge won't be affected by anything that would crawl out of that laboratory."

There is good reason to believe that the fear of experimentation will extend to the fear of some of the products of the genetic biotechnologies. Producers of protein-based end products, such as vaccines and hormones, may encounter little public resistance, but products which have been subjected to direct genetic manipulation may cause substantial marketing problems. This is a timely issue to consider in light of reported attempts by Winston Brill of Cetus Madison to gain permission this month from the Recombinant DNA Advisory Committee to field test genetically engineered plants.

Scientists and businessmen in the biotechnology community tend to forget how different the public's attitudes are about the exciting and commercially promising advances in so many areas of biotechnology. Although current data on public opinion about genetically engineered products does not exist, two studies conducted several years ago hint at the strength of common anxieties, at least in the U.S., about use of the technologies. One survey, conducted in 1977 by the National Assessment of Educational Progress, measured the attitudes of adults from 26-35 years of age towards recombinant
DNA technology. Almost two-thirds of this cross-section of the Sputnik generation opposed the use of the technology on any life form. A more recent survey was conducted in 1979 of 1,635 adults across the United States by the National Science Board of the National Science Foundation. The results were quite similar: 65 percent of the respondents believed that scientists should not conduct studies for creating new forms of life of any kind.

Science is not technology, of course, but there is no simple distinction in the public mind between these two pursuits. It is fair to expect that many of the fears of the scientific experimentation behind biotechnology will be transferred into fears about consumer products released into the environment.

A brief survey of marketing executives conducted by $\mathrm{BIO} / \mathrm{TECHNOLOGY}$ revealed that some of the top biotechnology-based corporations are concerned about possible reluctance to purchase biotechnology products. Companies involved with the genetic engineering of livestock have contacted farmers and determined that these consumers will generally trust the word of the Food and Drug Administration. The long-term marketing problems in this example and so many others may not rest with the intermediate purchaser. The problems will be encountered with the end product user, i.e., the buyer of the fastfood hamburger who tears foreign genes in the meal.

Now is the time for companies to anticipate the problems regarding public acceptance of biotechnology products. Industry must conduct a long-term self-analysis and support an extensive consumer education effort to assure the acceptability which biotechnology products deserve. The first step towards this goal is the recognition by industiy that overwhelming use of the language of the technology will intimidate a population which fears change and lacks understanding. The explosive growth of biotechnology is based in part on the optimism that careful, controlled observation and manipulation of life processes can lead to progress and eventual correction of unavoidable errors. Even to the nonscientist, the scientific jargon behind biotechnology expresses the confidence that life can be controlled by understanding codes, writing or rewriting, translating, editing, etc. People who do not understand life processes are more likely to think of biological structures as if they were card houses: if you insert or remove a card, the house may collapse.

An educational effort should be initiated by industry to prepare the public for biotechnology products, especially the products of genetic engineering. The language of this long-term marketing effort should de-emphasize man's power to change nature while illustrating ways in which technology mimics nature's genetic recombination. The language of the science and technology can then be introduced to the public in a way which expresses reliance upon observation and testing. A valuable consumer education effort would teach and enlist the trust of consumers.

In a culture which fears the rate of change wrought by biotechnology, industry could emphasize the evolutionContinued on page 211 
BIO/TECHNOLOGY (continued from page 137)

ary, cooperative advance between man and other life forms which biotechnology represents and counter the concept of natural disruption now associated with other technologies, especially nuclear technologies. To reinforce this effort, the tradition of fermentation, its safe use in the wine, cheese, and pharmaceutical industries, and its link to the new technologies should be introduced as new fermentation products are introduced. The stability, the safety, and the reliability of such procedures should also be stressed.

An industrial pre-marketing consumer education effort should also emphasize aspects of biotechnology which counter some of the current prejudices against other technologies. Consumers who rightly fear acid rain and meltdowns may be less reluctant to accept biotechnology products when the "clean" aspects of these processes are emphasized. The potentials for substituting enzymatic reactions for toxin-producing chemical reactions, the ability to develop non-polluting alternative energy forms, and the development of environmental monitoring products can be used as potent contrasts to the current view of technological evils.

The network for preparing consumers for biotechnology already exists in the marketing and public relations departments of corporations. The multimillion dollar budgets for reaching consumers through media and educational programs also exist. If corporations decide to use these resources with the same foresight and strategic planning which has characterized biotechnology research, the public can be prepared to accept and benefit from the proliferation of new products which will be introduced in the forseeable future.-Christopher Edwards

COMMENTARY (continued from page 174)

that the chances of finding something interesting would be greater with only 100 new compounds screened chemically and given biological tests, than with 10000 microbial strains examined by traditional techniques.

"The theory determines what one observes," Albert Einstein once said. The verdict of history may well be that Hans Zähner is the man who, during the 1980 s, altered the whole course of applied microbiology by crucially altering those rules of observation.

FINAL WORD (continued from page 212)

and practices of biotechnology and provides an insight into how, from the perspective of their individual disciplines, students will best be able to contribute to progress in the field. As a third possibility, the certificate program might arrange for students to spend time working in the laboratories of biotechnology companies where they will gain respect for applied science.

Certificate programs are not without problems. However, they are not disruptive to traditional departmental authority, nor do they widen the division between members of the program and their colleagues who do not participate in the program. They require no major changes in the operation or organization of university administrative structures, and certificate programs have the additional advantage in that they self destruct when interest in the field diminishes or disappears.

The system recommended here of a separately organized center and a certificate program in biotechnology complements the activities of traditional departments and offers the advantage of perpetuating a close association of research and teaching which is characteristic of quality higher education in America. It already has been implemented by some leading universities and is deserving of serious consideration by others intending to capitalize on the opportunity biotechnology has created.

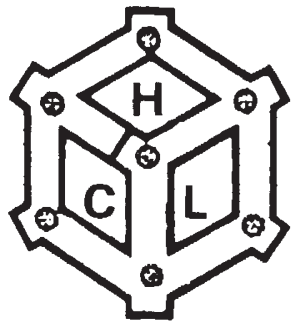

\section{RESEARCH \& DEVELOPMENT SERVICES in BIOTECHNOLOGY}

Since 1938 Haldane Consultants have been providing a research and development service in what is now widely known as biotechnology. A wide range of projects are progressed in their modern well equipped laboratories. Examples of projects are:-

Feasibility studies.
Development of process from inception to producing sufficient material for clinical or commercial evaluation.

\section{Assessing potential uses of raw materials and organic waste materials.}

\section{Process verification.}

Extraction and isolation.

The facilities include sterile product facilities, Category A containment and culture facilities for microorganisms, algae, animal cells and Plant cells in both batch and continuous culture systems.

Enquiries about specific projects should be addressed to the Director:

\author{
Haldane Consultants Limited, \\ 40, Nuffield Road, \\ Poole, Dorset BH17 7RA. \\ England.
}

Tel. Poole (0202) 678037

Circle No. 78 on Reader Service Card 